\title{
Chikungunya Virus Induces a More Moderate Cytopathic Effect in Mosquito Cells than in Mammalian Cells
}

\author{
Yong-Gang $\mathrm{Li}^{\mathrm{a}}$ Uamporn Siripanyaphinyo $^{\mathrm{b}}$ Uranan Tumkosit ${ }^{\mathrm{b}}$ \\ Nitchakarn Noranate ${ }^{b}$ Atchareeya A-nuegoonpipat ${ }^{c}$ Ran Tao $^{a}$ Takeshi Kurosu ${ }^{a}$ \\ Kazuyoshi lkuta ${ }^{a}$ Naokazu Takeda ${ }^{b}$ Surapee Anantapreecha ${ }^{c}$ \\ ${ }^{a}$ Department of Virology, Research Institute for Microbial Diseases, Osaka University, Osaka, Japan; ${ }^{\text {bSection of }}$ \\ Viral Infections, Thailand-Japan Research Collaboration Center on Emerging and Re-Emerging Infections, and \\ 'National Institute of Health, Department of Medical Sciences, Ministry of Public Health, Nonthaburi, Thailand
}

\section{Key Words}

Chikungunya virus $\cdot$ Apoptosis $\cdot$ C6/36 cells $\cdot$ Vero cells $\cdot$

Cytopathic effect $\cdot$ Persistent infection

\section{Abstract}

Objectives: Chikungunya virus (CHIKV) is an alphavirus belonging to the Togaviridae family. Alphaviruses cause a chronic non-cytopathic infection in mosquito cells, while they develop a highly cytopathic infection in cells originating from various vertebrates. In this study, we compared the cytopathic effect (CPE) induced by CHIKV in Vero cells and a mosquito cell line, C6/36 cells. Methods: CPE and the virus titers were compared between the CHIKV-infected C6/36 and Vero cells. Apoptosis was measured by TUNEL assay, and the differences between the $\mathrm{C} 6 / 36$ and Vero cells were compared. Results: CHIKV infection induced strong CPE and apoptosis in the Vero cells, but light CPE in the C6/36 cells. The virus titers produced in the $\mathrm{C} 6 / 36$ cells were much higher than those produced in the Vero cells. Conclusions: The reason $\mathrm{CHIKV}$ induced strong $\mathrm{CPE}$ is that this virus triggers strong apoptosis in Vero cells compared with $\mathrm{C} 6 / 36$ cells. CHIKV established a persistent infection in C6/36 cells after being passaged 20 times. CHIKV infection in mosquito cells was distinct from that in Vero cells. The cell and species specificity of CHIKV-induced cell death implies that the cellular and viral regulators involved in apoptosis may play an important role in determining the outcome of CHIKV infection.

Copyright $\odot 2012$ S. Karger AG, Basel

\section{Introduction}

Chikungunya virus (CHIKV), the causative agent of chikungunya fever, was first described in 1952 during an epidemic in Tanzania, East Africa [1]. CHIKV is a positive-sense single-strand RNA virus belonging to the genus Alphavirus in the family Togaviridae, and is maintained in two distinct transmission cycles, a sylvatic cycle and human-mosquito-human cycle. The scale of the epidemics for the former is smaller than the latter, and mainly confined within African countries involving primates, such as monkeys and forest-dwelling Aedes mosquitoes $[2,3]$. The main vectors of CHIKV transmission in the human-mosquito-human cycle are Aedes aegypti and Aedes albopictus. Since its first outbreak in East Africa,

\section{KARGER}

Fax +41613061234

E-Mail karger@karger.ch

www.karger.com
(C) 2012 S. Karger AG, Basel

0300-5526/13/0561-0006\$38.00/0

Accessible online at:

www.karger.com/int
Yong-Gang Li

Department of Virology

Research Institute for Microbial Diseases

Osaka University, Osaka (Japan)

Tel. +81 66879 8309, E-Mail yonggang@ biken.osaka-u.ac.jp 
CHIKV epidemics have often been characterized by long interepidemic periods of more than 10 years in many parts of Southern and Southeast Asia $[4,5]$. During the past 8 years, the major outbreaks have occurred on islands in the Indian Ocean. Reunion Island has been among the most severely hit, with one third of its population infected and more than 240 deaths recorded [6]. The symptoms of chikungunya generally start 4-7 days after the bite, and the acute phase, lasting 1-10 days, is characterized by painful polyarthralgia, high fever, asthenia, headache, vomiting, rash, and myalgia $[1,7]$. Chikungunya has affected as many as 3-4 million people in the Indian Ocean zone; it spread to Europe in 2005-2007, and recent outbreaks in Thailand have received considerable attention [8].

Both mosquito and vertebrate cell culture systems have been used to study CHIKV replication and pathogenesis [9]. Mosquito cells derived originally from $A$. albopictus larvae in particular have been employed in these studies. CHIKV is also able to infect a wide range of vertebrate cells and cell lines [10, 11], and most of these show an apparent cytopathic effect (CPE) [9]. A similar phenomenon was found in sindbis virus (SINV) infection, where almost all vertebrate cells died after infection, and the cell lines derived from mosquito are known to provide a long-term persistent infection [12]. The cell line derived from mosquito is known to provide a long-term persistent infection which is probably maintained by intracellular factors [13]. The viruses belonging to the alphavirus family have appeared to grow in cultured vertebrate and invertebrate cells [14]. Although alphaviruses cause encephalitis, neuronal apoptosis and death in mammals, they fail to kill the mosquitoes that can transmit these viruses. Therefore, host cell factors as well as viral factors regulate the outcome of the infection [15].

SINV is thought to cause a persistent infection in mosquito cells with moderate CPE in general [16]. We thought that CHIKV might also cause milder CPE in mosquito cells than in mammalian cells, and would lead to persistent infection in mosquito cells. The study on the pathogenicity of CHIKV is inadequate. Since Vero cells and C6/36 cells are commonly used in the propagation of flaviviruses such as dengue virus and togaviruses such as SINV [17-19], we used these two cells to study the pathogenesis of CHIKV infection. We found that CHIKV induced light $\mathrm{CPE}$ in mosquito cells, $\mathrm{C} 6 / 36$, but strong $\mathrm{CPE}$ in Vero cells. C6/36 produced higher titers of the progeny viruses compared to the Vero cells. CHIKV seems to establish a persistent infection in C6/36 cells when passaged
20 times. Interestingly, we also found that CHIKV induced stronger apoptosis in Vero cells than in C6/36 cells, although the mechanism is not yet known.

\section{Materials and Methods}

Virus and Cells

CHIKV Ross strain was propagated in Vero-E6 (Vero) cells which were maintained in MEM supplemented with $10 \%$ newborn calf serum and antibiotics at $37^{\circ}$ in $5 \% \mathrm{CO}_{2}$. C6/36 cells were maintained in Leibovitz's L-15 Media (Invitrogen, Carlsbad, Calif., USA) supplemented with $10 \%$ newborn calf serum, antibiotics and $1 \%$ TPB (Sigma, St. Louis, Mo., USA) at $32^{\circ}$. All experiments were performed in a biosafety level 3 containment laboratory.

\section{Immunofluorescence Assay}

CHIKV- and mock-infected cells were fixed with $4 \%$ paraformaldehyde, and incubated $30 \mathrm{~min}$ at $37^{\circ}$ with monoclonal antibody against the CHIKV E2 protein followed by FITC-conjugated anti-mouse IgG (Invitrogen) for $30 \mathrm{~min}$ at $37^{\circ}$. The monoclonal antibody was provided by Dr. P. Depres [20].

\section{Plaque Assay}

Vero cells were seeded at $1 \times 10^{6}$ cells per well in 6 -well plates and incubated at $37^{\circ}$ overnight. The cells were washed once with phosphate-buffered saline (PBS). Ten-fold serial dilutions of the virus were prepared in Hanks Buffer (Sigma-Aldrich), and $0.2 \mathrm{ml}$ of the solution was inoculated into each well and incubated for $1 \mathrm{~h}$ at $37^{\circ}$. During incubation, the plates were gently agitated every $15 \mathrm{~min}$. After the adsorption, the virus solution was removed and the cells washed three times with PBS. Two $\mathrm{ml}$ of $1 \%$ agrose in $2 \times$ MEM containing $0.5 \%$ FBS was layered onto the cell monolayers. The plates were incubated in a humidified incubator at $37^{\circ}$ with $5 \% \mathrm{CO}_{2}$ for 3 days, and then the agarose overlay was removed and washed with PBS. The plaques were visualized by staining the monolayer with $2 \mathrm{ml}$ of $0.25 \%$ crystal violet in $10 \%$ formaldehyde solution (Sigma-Aldrich) for $2 \mathrm{~h}$ at room temperature. The plates were washed and the plaques counted.

\section{TUNEL Staining}

The Vero and C6/36 cells $\left(2 \times 10^{6}\right)$ were infected at a multiplicity of infection (MOI) 1 , and apoptotic cells were characterized by terminal deoxynucleotidyl transferase-mediated dUTPbiotin nick end labeling according to the manufacturer's instructions (DeadEnd Fluorometric TUNEL System; Promega ). Briefly, after 24-hour postinfection (p.i.), the cells were fixed with $3 \%$ of paraformaldehyde in PBS containing $0.1 \%$ Triton X-100, washed with PBS three times, and incubated in a labeling reaction mixture containing terminal deoxynucleotidyl transferase enzyme, fluorescein isothiocyanate-conjugated nucleotide, and labeling buffer. The reaction was quenched in stop buffer, and the cells were washed with PBS several times. The cell nuclei were counterstained with propidium iodide (Sigma-Aldrich). Apoptosis was induced by a protein synthesis inhibitor, anisomycin, according to the manufacturer's instructions, and used as the positive control. 

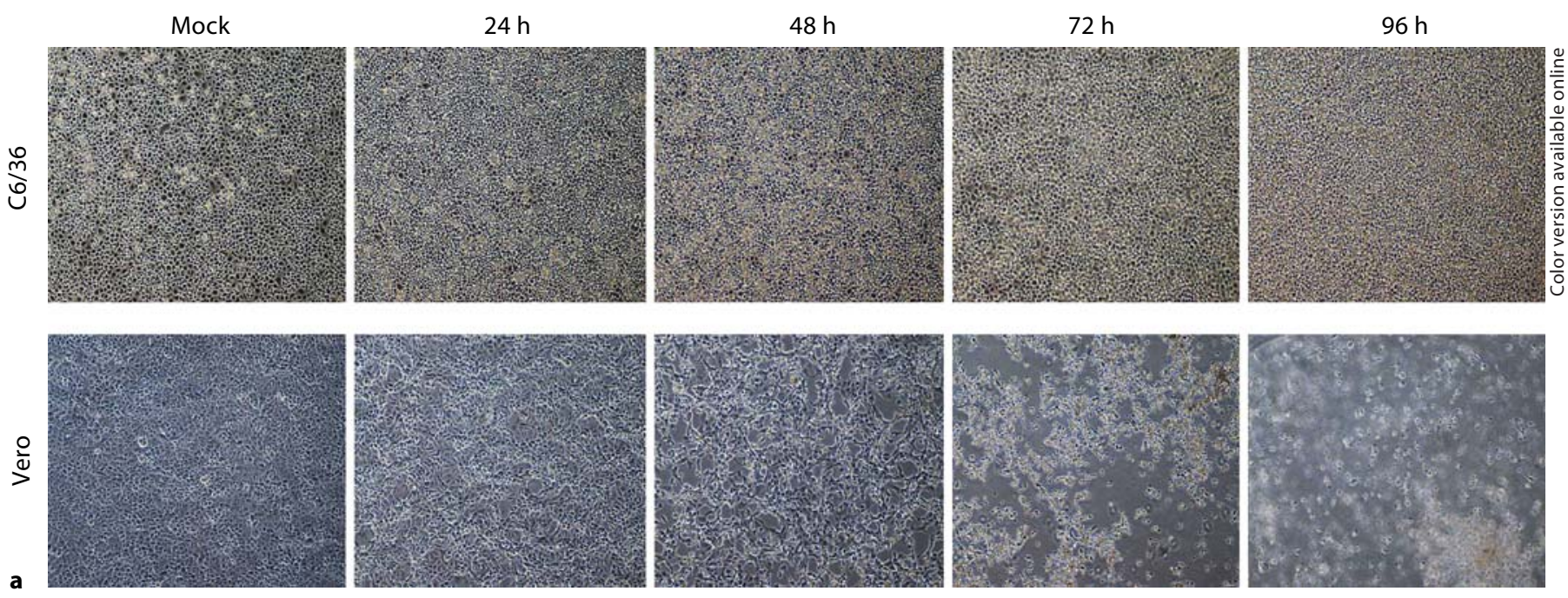

Fig. 1. a CPE of C6/36 and Vero cells infected with CHIKV. C6/36 and Vero cells were seeded in 12-well plates, infected with CHIKV at MOI 1 and incubated at $32^{\circ}$. CPE was observed under a microscope at 24, 48, 72 and 96 h p.i. Mock infection was shown at $96 \mathrm{~h}$ p.i. The morphology of the infected cells was photographed. $\times 400$. b Immunofluorescence staining of CHIKV-infected C6/36 cells. The cells were incubated with a monoclonal antibody against CHIKV E2 protein and labeled with FITC at 24, 48 and 72 h p.i. $\times 400$.
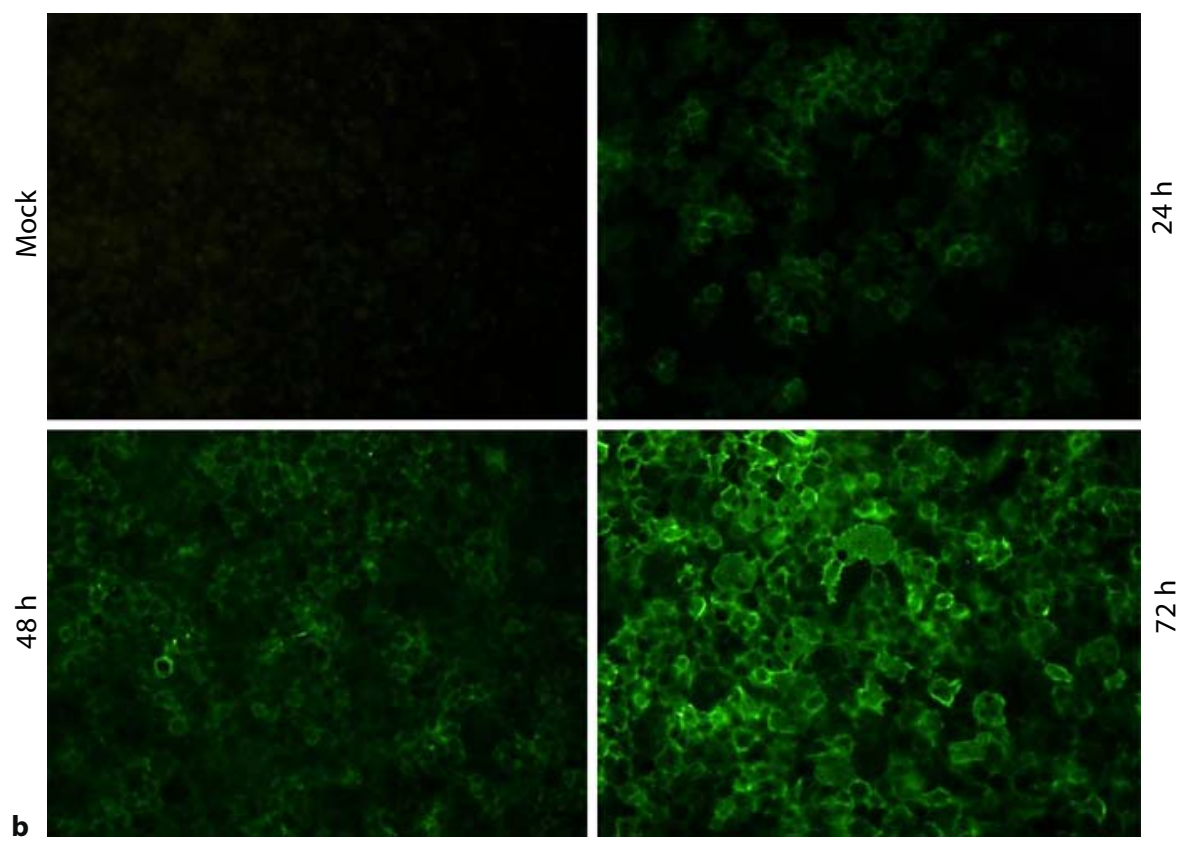

\section{Results}

CHIKV Induced Moderate CPEs in C6/36 and Strong

CPEs in Vero Cells

Vero cells and C6/36 cells were infected with CHIKV at MOI 1 . After 24, 48, 72, and 96 h p.i., the CPE was observed directly under a light microscope. In the primary experiment, we performed the experiment under different temperatures at 28,32 , and $37^{\circ}$. No effect was observed at $32^{\circ}$ on the viability of Vero cells after $48 \mathrm{~h}$ (data not shown), and both Vero and C6/36 cells were incubated at $32^{\circ}$ to avoid the effectiveness of the temperature.
The Vero cells showed apparent CPE at $48 \mathrm{~h}$ p.i., and nearly $90 \%$ of the cells died at 96 h p.i. In contrast, C6/36 showed minute $\mathrm{CPE}$ at $96 \mathrm{~h}$ p.i. (fig. 1a). To examine the expression of the viral E2 protein in C6/36 cells, an immunofluorescence assay was carried out at 24,48 , and $72 \mathrm{~h}$ p.i. The C6/36 cells were nearly $80 \%$ positive at $48 \mathrm{~h}$ p.i., and $100 \%$ at $72 \mathrm{~h}$ p.i. (fig. 1b). The Vero cells were $80 \%$ positive at $24 \mathrm{~h}$ p.i. (data not shown). These results indicated that the C6/36 cells showed moderate CPE under the condition in which the virus replication occurred in all of the infected cells. 
Fig. 2. Virus titers in the supernatant of CHIKV-infected C6/36 and Vero cells. C6/36 and Vero cells were infected with $\mathrm{CHIKV}$ at MOI 1 and incubated at $32^{\circ}$. After $24,48,72$, and $96 \mathrm{~h}$ p.i., the virus titers in the medium were determined by a plaque assay. The mean titers from three replicates are shown with the standard deviations. Statistical significance between the virus titers from the $\mathrm{C} 6 / 36$ and Vero cells at different time points $(\mathrm{p}<0.01)$ are marked with an asterisk.

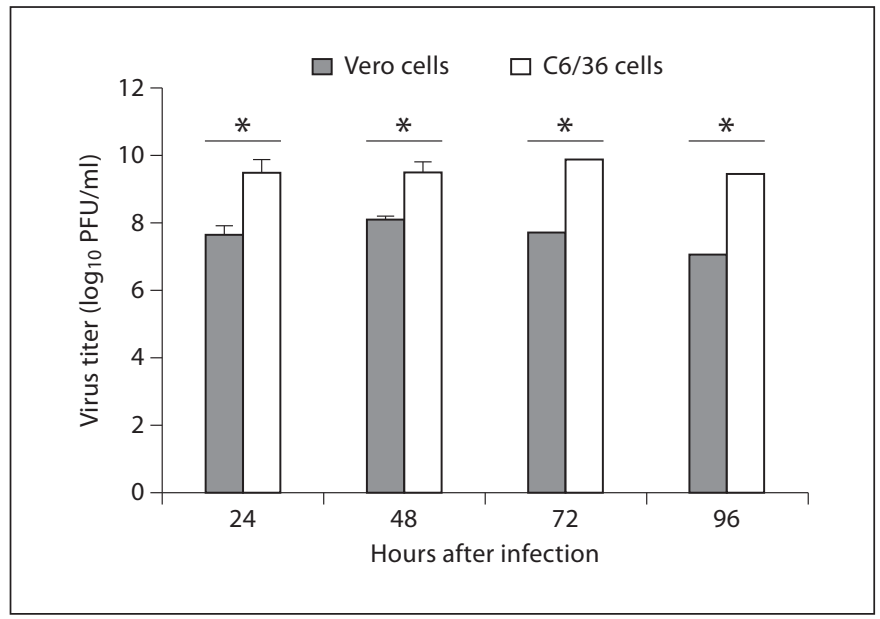

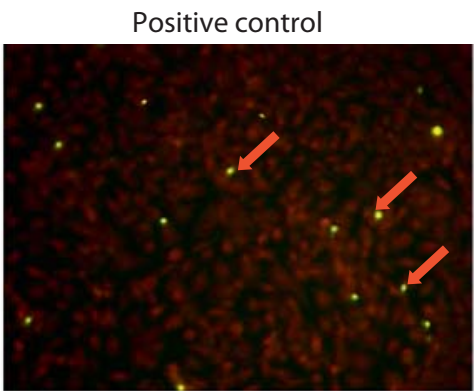
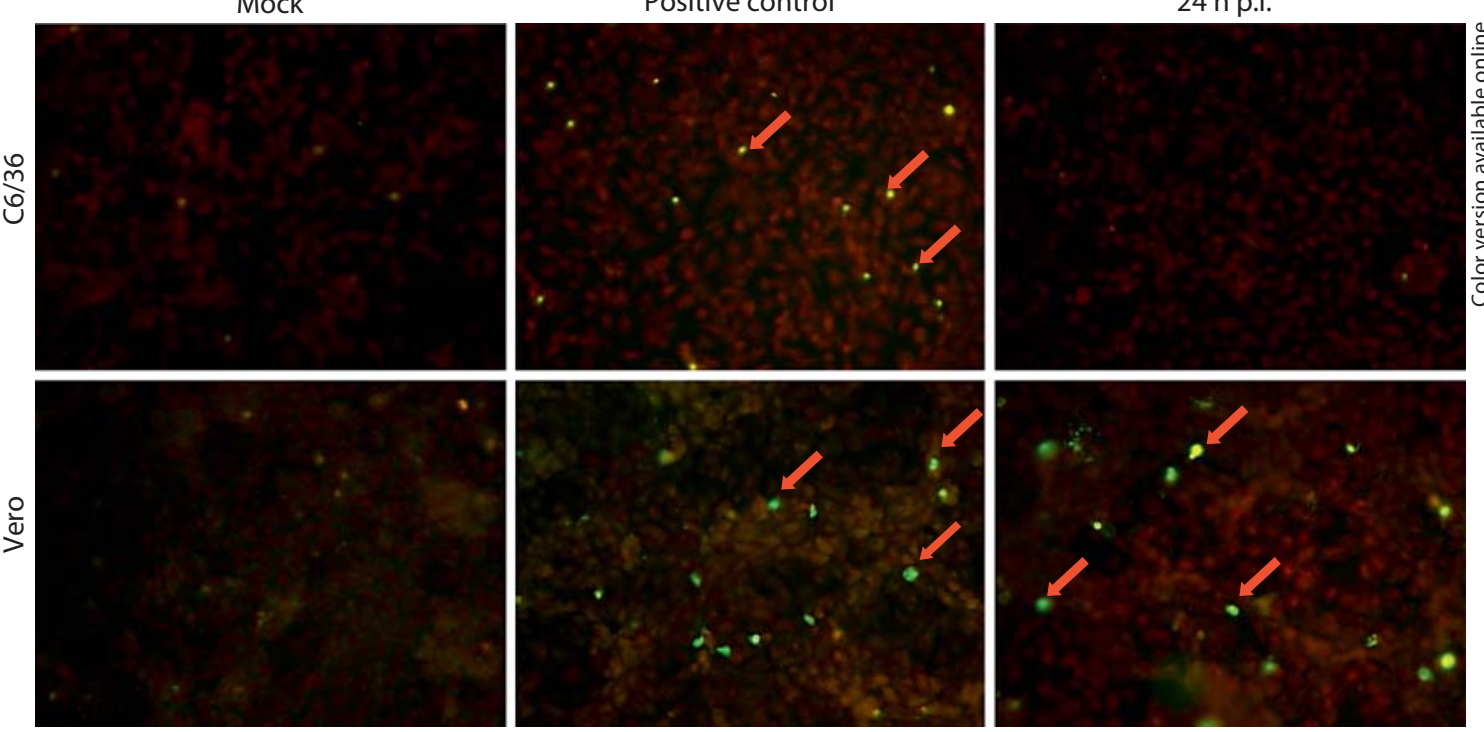

Fig. 3. TUNEL assay with CHIKV-infected C6/36 and Vero cells at $24 \mathrm{~h}$ p.i. at $32^{\circ}$. Cells with the arrows indicate apoptotic cells (green). Propidium iodide was used to stain the nuclei (red). The positive controls were cells treated with a protein synthesis inhibitor, anisomycin.

Virus Titers in Infected Vero and C6/36 Cells

The Vero and C6/36 cells were infected with CHIKV at MOI 1 , and the virus titers in the culture medium were measured by a plaque assay as described in 'Materials and Methods'. The mean virus titers produced in the C6/36 cells were $8.5 \times 10^{9}, 1.8 \times 10^{10}, 1.7 \times 10^{10}$ and $3 \times 10^{9}$ $\mathrm{PFU} / \mathrm{ml}$ at 24, 48, 72 and $96 \mathrm{~h}$ p.i., whereas those in the Vero cells were $9 \times 10^{7}, 1 \times 10^{8}, 7 \times 10^{7}$, and $1.5 \times 10^{7}$ $\mathrm{PFU} / \mathrm{ml}$ (fig. 2), indicating that the $\mathrm{C} 6 / 36$ cells produced higher viral titers than the Vero cells. The C6/36 cells produced a viral titer that was more than 100 times higher than the Vero cells. More than 100 times viruses were produced in the C6/36 cells. Although the Vero cells showed strong $\mathrm{CPE}$, the levels of virus replication were not efficient. These results coincided with those in a previous report obtained from SINV, in which CPE did not affect the virus titer that much [21]. 


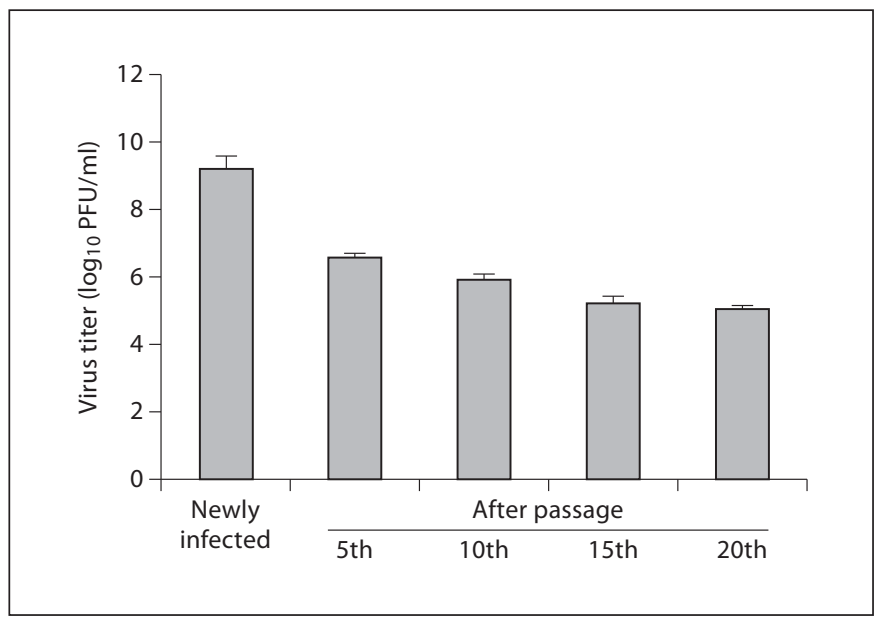

Fig. 4. Virus titers in the supernatant from CHIKV-infected $\mathrm{C} 6 / 36$ cells measured by a plaque assay. C6/36 cells were newly seeded every 3 days, and passaged 20 times at $32^{\circ}$.

\section{Apoptosis of Vero and C6/36 Cells after Infection with} CHIKV

In order to explore the mechanism of CHIKV-induced $\mathrm{CPE}$ in Vero cells, we analyzed apoptosis. Following infection or mock infection, the cells were fixed and subjected to TUNEL analysis as described in 'Materials and Methods'. As depicted in figure 3, the Vero cells at $24 \mathrm{~h}$ p.i. showed several apoptotic cells (green), but very few apoptotic cells were found in the CHIKV-infected C6/36 cells, suggesting that apoptosis may be one of the reasons why strong CPE was induced in the Vero cells.

\section{CHIKV Caused Persistent Infection in C6/36 Cells}

To examine whether CHIKV causes persistent infection in the mosquito cells, C6/36 cells were infected with CHIKV at MOI 1 , incubated for 5 days at $32^{\circ}$, and then passaged 20 times every 3 days using $1 \times 10^{6}$ cells for each passage. The medium was collected on day 3 in every passage, and the virus titers were determined and compared. The virus titers were $4.5 \times 10^{6}, 1.25 \times 10^{6}$, $2.5 \times 10^{5}$ and $1.5 \times 10^{5}$ in the 5 th, 10 th, 15 th, and 20 th passages, respectively, showing a decreasing trend, although the titers were not significantly different between each passage (fig. 4). After 20 passages, the expression of the viral antigen was examined by immunofluorescence assay, and nearly $100 \%$ of the cells were infected (data not shown). These results indicated that CHIKV had established a persistent infection in the C6/36 cells.

\section{Discussion}

Alphaviruses are generally thought to cause a lytic infection (apoptosis) in many mammalian cells, while they cause a persistent infection in mosquito cells exhibiting moderate CPE. For example, SINV causes acute cell death in most types of mammalian cells, and the infected cells display typical characteristics of apoptosis [21]. SINV is generally thought to cause only moderate $\mathrm{CPE}$ in mosquito cells with a persistent infection [16]. Similarly, dengue virus, a member of the flavivirus family, does not cause deleterious effects in mosquito cells and may result in persistent infection [22], suggesting that the cellular response to some of the members of the alphavirus and flavivirus families is highly related to the cell type. The reasons why SINV infection does not cause apoptosis in mosquito cells are still obscure.

CHIKV is a member of the alphavirus family, and causes a re-emerging mosquito-borne infection. In this study, we observed the same phenomenon in CHIKV as in SINV, in which CHIKV induced strong CPE and apoptosis in Vero cells, but light CPE and apoptosis in C6/36 mosquito cells. Apoptosis in HeLa cells induced by CHIKV was recently characterized, and this virus was found to trigger apoptosis through an early caspase-9dependent intrinsic mitochondrial pathway followed by an extrinsic caspase-8-dependent pathway [23]. CHIKV also exerts cytopathic activity through standard apoptosis machinery, in which it was shown that CHIKV releases viral proteins such as E1 and capsid, which shield into membrane vesicles. Engulfment of these CHIKV apoptotic blebs promotes the infection to the neighboring cells [23].

The cell and species specificity of SINV-induced cell death implies that cellular and viral regulators of apoptosis play important roles in determining the outcome of SINV infection. Nearly all vertebrate cell lines infected with SINVs do not survive after the infection. The mechanism by which CHIKV induced strong CPE in mammalian cells and weak CPE in mosquito cells is still not known. Apoptosis may be one of the reasons why CHIKV leads to cell death through strong CPE, because CHIKV induced strong apoptosis in Vero cells compared to C6/36 cells. Mosquito cells may carry apoptotic inhibitory genes.

Recently, virus-induced apoptosis mediated by an unfolded protein response (UPR) was hypothesized to be a crucial pathogenic event in viral infection: it creates conditions beneficial for an eventual viral infection. In general, newly synthesized secretory or membrane-bound 
proteins are unable to fold properly in the endoplasmic reticulum (ER), leading to induction of ER stress and subsequent elicitation of UPR [24]. Dengue virus-infected mosquito cells continued growing, implying that an antiER stress factor might be involved in the process of viral replication in mosquito cells [25]. Mosquito cells trigger a pathway that protects infected cells from death, which might be how Aedes mosquitoes resist dengue virus infection [26]. Activation of the UPR to cope with ER stress in the early phase of viral infection was shown in various vertebrate cells [27, 28]. However, flavivirus-infected mammalian cells ultimately face apoptosis through the effects of ER stress [29].

In this paper, we reported that CHIKV induced strong $\mathrm{CPE}$ in Vero cells but light CPE in mosquito cells, which may be one of the reasons why mosquito can be a natural host of CHIKV without being killed. In the mosquito body, the genetic factors that govern susceptibility to CHIKV infection contribute to the weak CPE. Most of the C6/36 cells did not die after infection with CHIKV and became persistent, even after being passaged 20 times. The CHIKV virus could make adaptation in C6/36 cells, or mutant viruses might be released during the passages, which made the virus titers show a decreasing trend during passages. C6/36 cells can produce a higher titer of CHIKV than Vero cells.

Apoptosis is another attractive candidate antiviral response in mosquitoes, given its importance in other virus-host systems [30]. Therefore, the mosquito cell may carry some host factors against apoptosis. It would be interesting to clarify the differences in apoptosis mechanisms between Vero and C6/36 cells in CHIKV infection, as this may help us to understand the mechanisms of CHIKV-induced diseases in humans. Further study is needed to clarify the mechanisms.

\section{Acknowledgements}

This study was supported, in part, by the program of the Founding Research Center for Emerging and Reemerging Infectious Diseases, which was launched through a project commissioned by the Ministry of Education, Culture, Sports, Science and Technology of Japan.

\section{References}

1 Robinson MC: An epidemic of virus disease in southern province, Tanganyika territory, in 1952-1953. I. Clinical features. Trans R Soc Trop Med Hyg 1955;49:28-32.

2 McIntosh BM JPGaDSI: Rural epidemic of chikungunya in South Africa with involvement of Aedes (Diceromyia) furcifer (Edwards) and baboons. S Afr J Sci 1977;73:267269.

3 Diallo M, Thonnon J, Traore-Lamizana M, Fontenille D: Vectors of chikungunya virus in Senegal: current data and transmission cycles. Am J Trop Med Hyg 1999;60:281-286.

-4 Munasinghe DR, Amarasekera PJ, Fernando CF: An epidemic of dengue-like fever in Ceylon (chikungunya) - a clinical and haematological study. Ceylon Med J 1966;11:129-142.

5 Pavri K: Disappearance of chikungunya virus from india and south east asia. Trans $\mathrm{R}$ Soc Trop Med Hyg 1986;80:491.

6 Schwartz O, Albert ML: Biology and pathogenesis of chikungunya virus. Nat Rev Microbiol 2010;8:491-500.

7 Lumsden WH: An epidemic of virus disease in southern province, Tanganyika territory, in 1952-1953. II. General description and epidemiology. Trans R Soc Trop Med Hyg 1955; 49:33-57.
8 Pongsiri P, Auksornkitti V, Theamboonlers A, Luplertlop N, Rianthavorn P, Poovorawan Y: Entire genome characterization of chikungunya virus from the 2008-2009 outbreaks in Thailand. Trop Biomed 2010;27: 167-176.

-9 Sourisseau M, Schilte C, Casartelli N, Trouillet C, Guivel-Benhassine F, Rudnicka D, SolFoulon N, Le Roux K, Prevost MC, Fsihi H, Frenkiel MP, Blanchet F, Afonso PV, Ceccaldi PE, Ozden S, Gessain A, Schuffenecker I, Verhasselt B, Zamborlini A, Saib A, Rey FA, Arenzana-Seisdedos F, Despres P, Michault A, Albert ML, Schwartz O: Characterization of reemerging chikungunya virus. PLoS Pathog 2007;3:e89.

-10 Solignat M, Gay B, Higgs S, Briant L, Devaux C: Replication cycle of chikungunya: a reemerging arbovirus. Virology 2009;393: 183-197.

11 Her Z, Malleret B, Chan M, Ong EK, Wong SC, Kwek DJ, Tolou H, Lin RT, Tambyah PA, Renia L, Ng LF: Active infection of human blood monocytes by chikungunya virus triggers an innate immune response. J Immunol 2010;184:5903-5913.

12 Karpf AR, Lenches E, Strauss EG, Strauss JH, Brown DT: Superinfection exclusion of alphaviruses in three mosquito cell lines persistently infected with sindbis virus. J Virol 1997;71:7119-7123.
13 Karpf AR, Blake JM, Brown DT: Characterization of the infection of Aedes albopictus cell clones by sindbis virus. Virus Res 1997; 50:1-13.

14 Brown DT: Alphavirus growth in cultured vertebrate and invertebrate cells; in Mayo MA, Herrop KA (eds): Vectors in Virus Biology. New York, Academic Press, 1984, pp 113-133.

15 Irusta PM, Lamos E, Galonek HL, Vander Maten MA, Boersma MC, Chen YB, Hardwick JM: Regulation of apoptosis by viruses that infect insects. Arch Virol Suppl 2004; 171-178.

16 Karpf AR, Brown DT: Comparison of sindbis virus-induced pathology in mosquito and vertebrate cell cultures. Virology 1998;240: 193-201.

17 Wang H, Blair CD, Olson KE, Clem RJ: Effects of inducing or inhibiting apoptosis on sindbis virus replication in mosquito cells. J Gen Virol 2008;89:2651-2661.

18 Dash PK, Tiwari M, Santhosh SR, Parida M, Lakshmana Rao PV: RNA interference mediated inhibition of chikungunya virus replication in mammalian cells. Biochem Biophys Res Commun 2008;376:718-722. 
19 Lin CC, Yang CF, Tu CH, Huang CG, Shih YT, Chuang CK, Chen WJ: A novel tetraspanin C189 upregulated in C6/36 mosquito cells following dengue 2 virus infection. Virus Res 2007;124:176-183.

20 Brehin AC, Rubrecht L, Navarro-Sanchez ME, Marechal V, Frenkiel MP, Lapalud P, Laune D, Sall AA, Despres P: Production and characterization of mouse monoclonal antibodies reactive to chikungunya envelope E2 glycoprotein. Virology 2008;371:185-195.

-21 Nava VE, Rosen A, Veliuona MA, Clem RJ, Levine B, Hardwick JM: Sindbis virus induces apoptosis through a caspase-dependent, CrmA-sensitive pathway. J Virol 1998;72: 452-459.
22 Chen WJ, Chen SL, Fang AH: Phenotypic characteristics of dengue 2 virus persistently infected in a C6/36 clone of Aedes albopictus cells. Intervirology 1994;37:25-30.

-23 Krejbich-Trotot P, Denizot M, Hoarau JJ, Jaffar-Bandjee MC, Das T, Gasque P: Chikungunya virus mobilizes the apoptotic machinery to invade host cell defenses. FASEB J 2011;25:314-325.

24 Yoshida H: ER stress response, peroxisome proliferation, mitochondrial unfolded protein response and Golgi stress response. IUBMB Life 2009;61:871-879.

25 Boya P, Cohen I, Zamzami N, Vieira HL, Kroemer G: Endoplasmic reticulum stressinduced cell death requires mitochondrial membrane permeabilization. Cell Death Differ 2002;9:465-467.

26 Chen TH, Tang P, Yang CF, Kao LH, Lo YP, Chuang CK, Shih YT, Chen WJ: Antioxidant defense is one of the mechanisms by which mosquito cells survive dengue 2 viral infection. Virology 2011;410:410-417.
27 Jindadamrongwech S, Thepparit C, Smith DR: Identification of GRP 78 (BiP) as a liver cell expressed receptor element for dengue virus serotype 2. Arch Virol 2004;149:915927.

28 Umareddy I, Pluquet O, Wang QY, Vasudevan SG, Chevet E, Gu F: Dengue virus serotype infection specifies the activation of the unfolded protein response. Virol J 2007;4:91.

29 Yu CY, Hsu YW, Liao CL, Lin YL: Flavivirus infection activates the XBP1 pathway of the unfolded protein response to cope with endoplasmic reticulum stress. J Virol 2006;80: 11868-11880.

30 Hay S, Kannourakis G: A time to kill: viral manipulation of the cell death program. J Gen Virol 2002;83:1547-1564. 